\title{
Uveal Melanoma Patient-Derived Xenografts
}

\author{
Guillaume Carita $^{\mathrm{a}}$ Fariba Némati $^{\mathrm{a}}$ Didier Decaudin ${ }^{\mathrm{a}}{ }^{\mathrm{b}}$ \\ aLaboratory of Preclinical Investigation, Translational Research Department, and \\ ${ }^{b}$ Department of Medical Oncology, Institut Curie, Paris, France
}

\section{Key Words}

Uveal melanoma · Patient-derived xenograft · Gene mutations · Genomic and gene expression profiles $\cdot$ In vivo experiments

\begin{abstract}
The prognosis of uveal melanoma (UM) remains poor due to a high risk of metastatic disease. No effective therapies have been described for metastatic UM, and new therapies are needed to improve the outcome for these patients. To achieve this goal, new preclinical animal models are needed. Existing animal models, including genetically engineered mice and orthotopic xenograft models in immunodeficient animals, are inadequate for modelling human disease. In this review, we present the development and characterization of a large panel of UM patientderived xenografts (PDXs). Based on molecular features as identified in patient tumors, i.e. histopathological classification, specific gene mutations, as well as genomic and gene expression profiles, we show that PDXs closely resemble many important genetic and histological aspects of human UM with a remarkable stability over the course of their in vivo maintenance. Our techniques for establishing and maintaining primary UMs as xenograft tumors in immunodeficient mice provide a high degree of genetic conservation between the primary tumor and its xenograft over multiple in vivo passages. These models therefore represent a significant advance in the resources available for drug screening and studies of the pathogenesis of UM.
\end{abstract}

(c) 2015 S. Karger AG, Basel

\section{Introduction}

The continuously growing body of knowledge concerning oncogenesis allows the identification of new molecular pathways and therefore of new potential targeted compounds, increases the efficacy of antitumor treatments, and improves the outcome of cancer patients. However,

Dr. Didier Decaudin, MD, PhD 
the very large number of therapeutic candidates would require numerous clinical trials to assess their efficacy and identify predictive markers of response and/or resistance. This issue is reinforced by the modern management of cancer patients in which multiple targeted therapies are combined. As early clinical trials may show unexpected and unacceptable toxicities, and as they are time-consuming and expensive, it is of importance that new compounds are strictly selected. Such screening is particularly requested in rare diseases for which clinical studies are more difficult to repeat. In order to identify the potentially most effective and most specific molecules, the preclinical investigation of new compounds constitutes a crucial step in the drug development process, highlighting the role of relevant tumor models.

Three main categories of preclinical cancer models are generally used in preclinical investigations, namely (1) genetically engineered models (GEMs), (2) xenografts derived from human tumor cell lines, and (3) human tumor fragments obtained from patients directly transplanted into immunodeficient mice without intermediate in vitro passage, which are known as patientderived xenografts (PDXs). Each of these models possesses theoretical and practical advantages and disadvantages: on the one hand, PDXs accurately reproduce the marked heterogeneity of human malignancies, particularly when large panels of a specific tumor type are available [1]. Procedures for the assessment of a drugs' therapeutic efficacy have been well standardized and readily allow the evaluation of drug combinations, particularly for the purposes of objective biostatistical assessment [2]. Finally, the possibility of ex vivo genetic or therapeutic manipulations before xenotransplantation constitutes an argument in favor of their use. On the other hand, GEMs often provide specific molecular targets highly suited to the preclinical assessment of the corresponding targeted compounds. Tumor growth occurs spontaneously in situ and in organ-specific sites, reproducing the situation observed in human cancers. Interactions between tumor and stroma, i.e. neoangiogenesis and the action of the innate immune system, appear to closely mimic human situations. In contrast, assessment of therapeutic efficacy could be hampered in case of nonsuperficial, delayed, or a low incidence of tumor growth.

With a stable annual incidence of 4.3 per million (95\% confidence interval: $4.1-4.5$ ) in the United States, i.e. 1,200-1,500 new cases each year, uveal melanoma (UM) is a rare human malignant disease [3] but constitutes the most common primary intraocular tumor in adults [4]. In almost all cases, it arises in the pigmented uveal tract including the choroid, ciliary body, and iris [5]. In case of advanced local disease, retinal detachment and loss of vision can occur. In contrast to cutaneous melanoma, an association between UM and ultraviolet light has not been clearly established [6,7]. While metastatic UM is extremely rare at the time of initial diagnosis, and despite a 10 -year local control rate of $95 \%$, up to $50 \%$ of UM patients may die from metastases [8]. The liver represents the most frequent site of metastases (89\% of cases) and the only diagnosed site of dissemination in about half of the patients [9].

Hence, to improve the outcome of UM patients, new therapies are warranted. However, because of the very low incidence of the disease, it would be difficult to conduct numerous clinical trials to test the efficacy of innovative therapeutic agents administered alone or in combination. It is therefore mandatory to develop preclinical models that accurately reproduce the molecular features of human UM and display a high predictive value for clinical efficacy in patients. The aim of this review is to present data on the development of UM PDXs from our laboratory $[10,11]$.

\section{Establishment of a Panel of UM PDXs}

To allow in vivo pharmacological experiments directed by tumor molecular features, one needs to have a panel of human tumors grown in mice. We obtained $90 \mathrm{UM}$ samples from primary tumors or metastases and were able to successfully develop 25 viable PDXs in SCID 
Table 1. Characteristics of UM PDXs

\begin{tabular}{|c|c|c|c|c|c|c|c|c|c|c|c|c|c|c|c|}
\hline \multirow[t]{3}{*}{ PDXs } & \multirow{2}{*}{\multicolumn{2}{|c|}{ Histology }} & \multicolumn{8}{|c|}{ Gene mutations } & \multicolumn{4}{|c|}{ Chromosome imbalances } & \multirow{3}{*}{$\begin{array}{l}\mathrm{GE} \\
\mathrm{X}\end{array}$} \\
\hline & & & \multicolumn{2}{|c|}{$G N A Q$} & \multicolumn{2}{|c|}{ GNA11 } & \multicolumn{2}{|c|}{$B A P 1$} & \multicolumn{2}{|c|}{ SF3B1 } & \multicolumn{2}{|l|}{3} & \multicolumn{2}{|l|}{$8 q$} & \\
\hline & $\mathrm{P}$ & $X$ & $\mathrm{P}$ & $\mathrm{X}$ & $\mathrm{P}$ & $\mathrm{X}$ & $\mathrm{P}$ & $\mathrm{X}$ & $\mathrm{P}$ & $\mathrm{X}$ & $\mathrm{P}$ & $\mathrm{X}$ & $\mathrm{P}$ & $\mathrm{X}$ & \\
\hline MP34 & $\mathrm{E}$ & $\mathrm{E}$ & 0 & 0 & + & + & 0 & 0 & & + & & $-3 p$ & & $+8 q^{\circ}$ & \\
\hline MP38 & $\mathrm{S}$ & $E$ & + & + & 0 & 0 & + & + & & 0 & isod & -3 & $+8 q$ & $+8 q$ & 2 \\
\hline MP41 & $\mathrm{E}$ & $\mathrm{E}$ & 0 & 0 & + & + & 0 & 0 & & 0 & $\mathrm{~N}$ & $\mathrm{~N}$ & $+8 q^{\circ}$ & $+8 \mathrm{q}^{\circ}$ & 1 \\
\hline MP42 & $\mathrm{S}$ & $\mathrm{S}$ & 0 & 0 & + & + & + & + & & 0 & & & & & 2 \\
\hline Mp46 & $E$ & $\mathrm{M}$ & & + & & 0 & & 0 & & 0 & -3 & isod & & & \\
\hline MP47 & $E$ & $E$ & 0 & 0 & + & + & + & + & & 0 & -3 & & $+8 q$ & & 2 \\
\hline MP55 & $\mathrm{M}$ & $E$ & 0 & 0 & + & + & + & + & & & -3 & -3 & $+8 q$ & $+8 q$ & 2 \\
\hline MP65 & & & 0 & 0 & + & + & + & + & & & -3 & -3 & $+8 \mathrm{q}$ & $+8 q$ & 2 \\
\hline MP71 & $E$ & $E$ & + & + & 0 & 0 & 0 & 0 & & 0 & -3 & -3 & $+8 q$ & $+8 q$ & 2 \\
\hline MP77 & $E$ & $E$ & 0 & 0 & + & + & 0 & 0 & & 0 & -3 & -3 & $+8 q$ & $+8 q$ & 2 \\
\hline MP80 & $\mathrm{M}$ & $\mathrm{M}$ & 0 & 0 & + & + & 0 & 0 & & 0 & -3 & -3 & $+8 q$ & $+8 \mathrm{q}$ & 2 \\
\hline MM26 & $\mathrm{M}$ & $E$ & + & + & 0 & 0 & 0 & 0 & & + & -3 & -3 & $+8 q$ & $+8 q$ & 1 \\
\hline MM28 & $\mathrm{M}$ & $E$ & & 0 & & + & & + & & 0 & & isod & & & \\
\hline MM33 & $E$ & $E$ & + & + & 0 & 0 & 0 & 0 & & 0 & $\mathrm{~N}$ & $\mathrm{~N}$ & $+8 q$ & $+8 q$ & 1 \\
\hline MM52 & $\mathrm{M}$ & $\mathrm{M}$ & & + & 0 & 0 & + & + & & + & -3 & -3 & $\mathrm{~N}$ & $+8 q$ & 2 \\
\hline MM66 & $E$ & $E$ & & 0 & & + & & 0 & & 0 & $\mathrm{~N}$ & $\mathrm{~N}$ & $+8 q$ & $+8 q$ & 1 \\
\hline MM74 & $E$ & $E$ & 0 & 0 & + & + & + & + & & & -3 & -3 & $+8 q$ & $+8 q$ & 2 \\
\hline
\end{tabular}

$\mathrm{P}=$ Patient tumors; $\mathrm{X}=$ corresponding xenografts; $\mathrm{E}=$ epithelioid cells; $\mathrm{M}=$ mixed cells; $\mathrm{S}=$ spindle cells. Gene mutations: 0 = nonmutated $++=$ mutated. Chromosome imbalances: isod = isodisomy; $-=$ loss; $+=$ gain; ${ }^{\circ}=$ partial alteration; $\mathrm{N}=$ normal; empty = no data available. GE = Classification by gene expression [26]: 1 = low-risk tumors; 2 = high-risk tumors.

mice (take rate, 28\%) [10]. It is noteworthy that no clinical features of tumor presentation, i.e. tumor site, diameter, thickness, retinal detachment, or extraocular growth, nor any histopathological characteristics, such as epithelioid, spindle, or mixed cell morphology, ciliary body involvement, or mitotic index, were predictive of in vivo tumor growth [10]. With regard to the mutation status of the transplanted patient tumors, we found that significantly fewer GNAQ-mutated tumors were able to grow in mice $\left(\mathrm{p}<10^{-3}\right)$, and, inversely, a significantly higher proportion of GNA11-mutated tumors were able to grow after in vivo transplantation ( $\mathrm{p}<0.05$ ). In contrast, no impact of BAP1 mutation was observed on in vivo tumor take [11]. Similarly, we did not find that the presence of monosomy 3 increased in vivo tumor growth [10]. However, one predictor was found: the tumor take rate was significantly increased when the tumor tissue was derived from metastases versus primary intraocular tumors, with take rates of 52.9 and $21.9 \%$, respectively $(p=0.02)$ [10].

In this panel of UM PDXs, an extensive characterization has been performed to validate their in vivo preclinical use. This characterization included histopathological analyses as well as genetic, genomic, and gene expression profiles. A double comparison was performed, as we did not only compare the PDXs to their original patient samples, but also examined PDXs at various subsequent in vivo passages. All these data are summarized in table 1.

\section{Histopathological Features of UM PDXs}

In the 16 UM PDXs that were compared to their original human tumor, we observed a complete concordance in 11 cases in terms of histopathological classification (pure epithelioid cells, mixed cells with a predominance of epithelioid cells, or spindle cells) [10]. In 


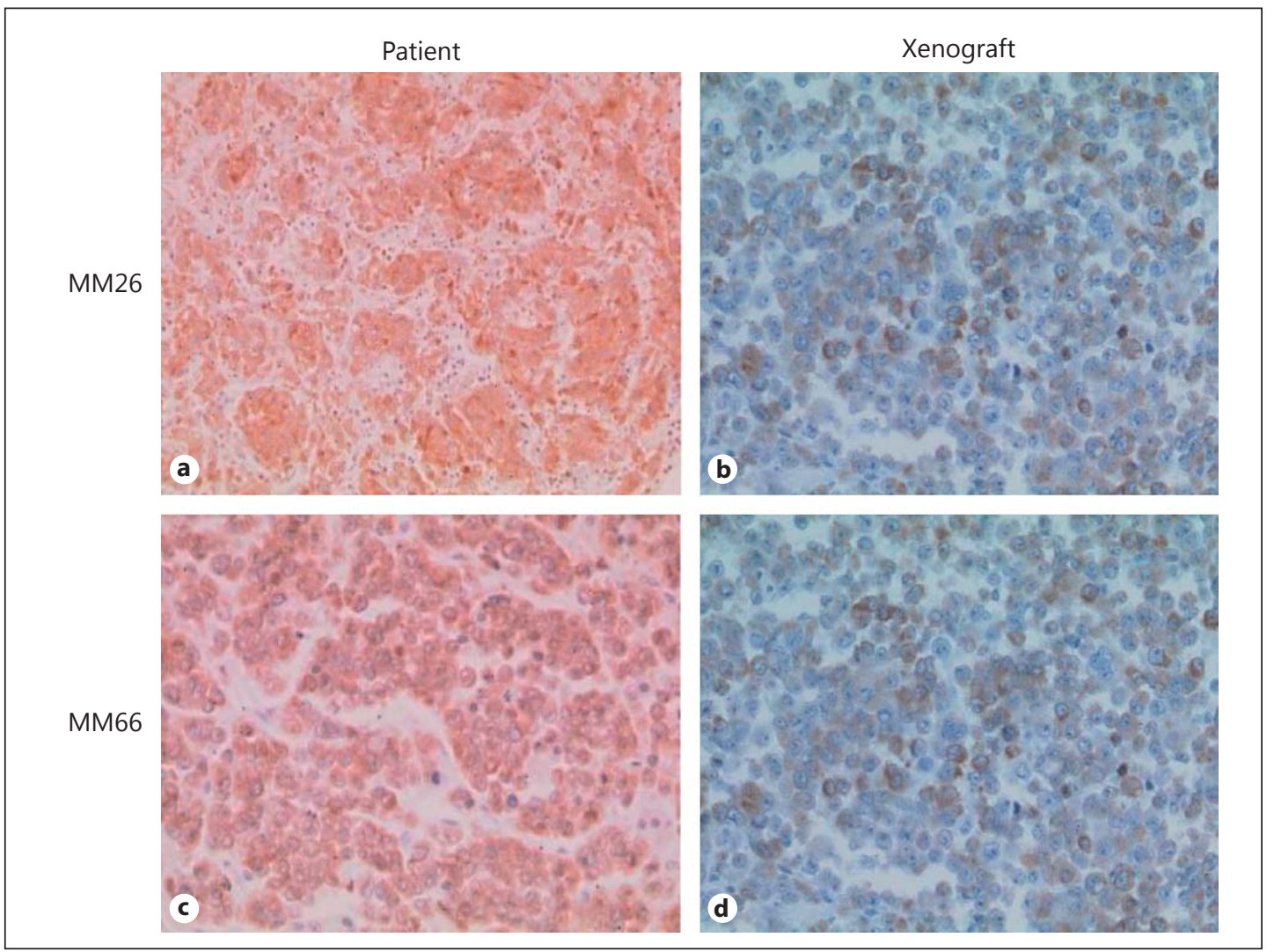

Fig. 1. Histopathologic features of two patient tumors and corresponding xenografts. a MM26: patient (mixed cells). b MM26: xenograft (epithelioid cells). c MM66: patient (epithelioid cells). d MM66: xenograft (epithelioid cells). HE. $\times 200$.

3 cases in which the patient's tumor showed a mixed cellularity, xenografts were defined as epithelioid cells, and in 1 case of a patient's epithelioid cell tumor, the corresponding PDX showed mixed cellularity. Finally, in the last case, tumor cells were of the epithelioid type in PDX and of the spindle cell type in the patient's tumor. This apparent discrepancy could be explained by the presence of a small epithelioid contingent not observed in the histologic section, which may have possessed a higher capacity for in vivo engraftment than spindle tumor cells. Two examples are shown in figure 1.

\section{Genomic Alterations of UM PDXs}

Various recurrent genomic abnormalities as chromosomal losses (L) or gains (G) have been observed in human UM. The two most frequent alterations concern L3 (short and long arms of chromosome 3) and G8q. However, some other genomic alterations have been observed, i.e. G6p, L6q, L8 (short and long arms), L16q, L1p, and others. Some genomic alterations have been associated with a worse prognosis, such as genetic imbalance [12], L3 [13, $14]$, G8q [15, 16], and L1p [16]. In contrast, G6p has been correlated with a better prognosis [16]. Concomitant abnormalities have also been described and may impact the prognosis of UM patients [17-19]. 
In a previous study [11], of the 13 analyzed PDXs, we observed a loss of chromosome 3 in 10 cases $(77 \%)$ and a gain of $8 q$ in all cases. Other abnormalities were also found, i.e. loss of $1 p$ in 8 cases (62\%), gain of $1 q$ in 8 cases (62\%), gain of $6 p$ in 6 cases $(46 \%)$, loss of $6 q$ in 11 cases (46\%), gain of $8 p$ in 7 cases (54\%), and loss of $16 q$ in 6 cases (46\%). These genomic profiles reveal that all UM PDXs are derived from high-risk tumors. When PDXs are compared to their originated patient tumors, the frequent chromosomal alterations in up to $50 \%$ of cases in patients' tumors are similar in the corresponding xenografts, with a total correlation score of 0.89 . This strong correlation per model is significantly higher than the correlation observed between all samples by study of correlation distributions with the KolmogorovSmirnov test $(\mathrm{p}<2.2 \mathrm{e}-16)$. When various in vivo passages (P1, P4, and P9) are compared for the same PDXs, we found a high level of conservation of genomic profiles. Given the long interval between the first and the ninth passage (between 18 and 38 months), we can conclude that there is a high degree of genomic stability in these PDXs.

\section{Genetic Features of UM PDXs}

Various gene mutations have been described in human UM tumors, i.e. exclusive mutations of the two GTPase genes GNAQ [guanine nucleotide-binding protein $\mathrm{G}(\mathrm{q})$ subunit alpha] and GNA11 [guanine nucleotide-binding protein G(q) subunit 11] have been observed in about $80 \%$ of cases [20-22], mutations in the BAP1 gene (BRCA1-associated protein 1) in about $40-50 \%$ of cases [23], and mutations in the $S F 3 B 1$ gene (splicing factor 3B subunit 1) in about $20 \%$ of cases [24]. In contrast to cutaneous melanomas in which BRAF mutations have been found in $66 \%$ of cases [25], no BRAF mutations, except in one series, have been found in UM tumors.

As shown in table 1, among the 17 studied PDXs, GNAQ, GNA11, BAP1, and SF3B1 mutations have been found in 6 (35\%), 11 (65\%), 8 (47\%), and $3(18 \%)$ cases, respectively. Most of the GNAQ mutations observed were missense mutations in exon 5 (c.626A $>$ C), changing a glycine to a proline, leading to a major modification of the alpha subunit. GNA11 mutations were mostly found in exon 5 on the same Gln209. All BAP1 mutations are deleterious mutations that impact the nucleus localization of the protein. No BRAF mutations were detected. In all cases, a complete concordance was observed between the PDXs and the original patient's tumor.

\section{Gene Expression Profiles of UM PDXs}

Using Affymetrix GeneChip ${ }^{\circledR}$ Human Exon 1.0 ST arrays, 10 coupled original tumors and their corresponding PDXs have been studied. About 700 genes were found to be differentially expressed between patient tumors and xenograft (P1 and P4), representing 3\% of all genes available on the microarrays. About two thirds of the 700 genes differentially expressed between patient tumors and xenografts were overexpressed in the patient tumors, and about one third of the genes were overexpressed in the xenografts [11]. Enrichment analysis of these differentially expressed genes by hypergeometric tests revealed gene overexpression in the immune system, extracellular matrix, and angiogenesis biological process categories in patient tumors compared to xenografts; conversely, overexpression of genes of the cell cycle, DNA repair, and kinase activity biological process categories were found in xenografts compared to patient tumors. Such downregulation of genes involving the immune system, extracellular matrix, and angiogenesis may be due to the presence of human stromal cells in patient tumors and murine stromal cells in xenografts and may explain the relatively low 


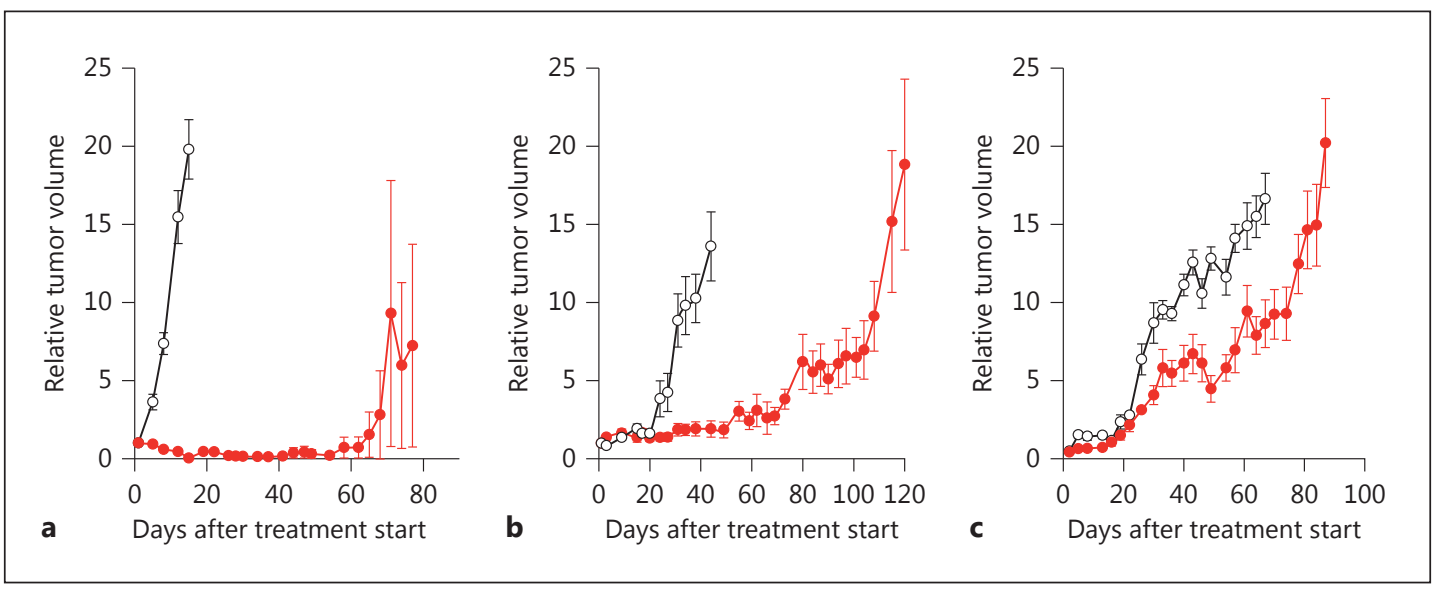

Fig. 2. In vivo response to fotemustine. Mice with PDX MP77 (a), MM26 (b), and MM66 (c) were treated with fotemustine intraperitoneally at a dose of $30 \mathrm{mg} / \mathrm{kg}$ on days 1-3, every 3 weeks for 3 cycles (closed circles). Controls (open circles) were treated with $0.9 \% \mathrm{NaCl}$. Tumor growth was evaluated by plotting the mean of the relative tumor volume \pm SD per group.

clustering of patient tumors and xenografts. Finally, when gene expression profiles were compared for the same PDX at various passages, we found that no genes were differentially expressed (false discovery rate $<0.01$ ) between xenografts at very early and early in vivo passages.

To complete the gene expression analyses of our UM PDXs panel, we evaluated the previously reported 15-gene expression profiling (GEP) assay [26] that discriminates between primary UMs and categorizes them into two prognostic subgroups (class 1 - low metastatic risk, and class 2 - high metastatic risk). As we reported earlier [11], among 14 xenografts analyzed, 10 were classified as high risk and 4 as low risk by using GEP, which shows that poor prognosis UM tumors were overrepresented in our PDX panel. Importantly, a complete concordance was found between patient tumors and their corresponding xenografts in terms of GEP classification.

\section{Pharmacological Characterization of UM PDXs}

In order to validate the predictive value of PDXs for treatment efficacy, determination of the response to standard chemotherapies constitutes a first and necessary step of PDX characterization in most human cancers. As no efficient cytotoxic agent has been reported for UM as yet, the applicability of PDXs needs to be investigated. This is particularly highlighted in the current molecular management of malignancies where the real issue concerns in fact the predictive value of PDXs as comparted to the clinical efficacy of targeted therapies used alone or in combinations. Moreover, it is important to mention that targeted therapies could not be directed by exclusive classical MTD (maximal tolerated dose) criteria, as is often done with standard chemotherapeutic agents. Indeed, what is probably of high importance for targeted therapies is obtaining pharmacodynamic data that are able to state how well the target is reached, how this targeting impacts the tumor responses, and how the therapy can be improved in low-responding or refractory patients and in case of acquired resistance.

Despite all of these considerations, we evaluated the efficacy of well-used standard chemotherapies in UM patients, i.e. of the drugs fotemustine and dacarbazine/temozolomide. 


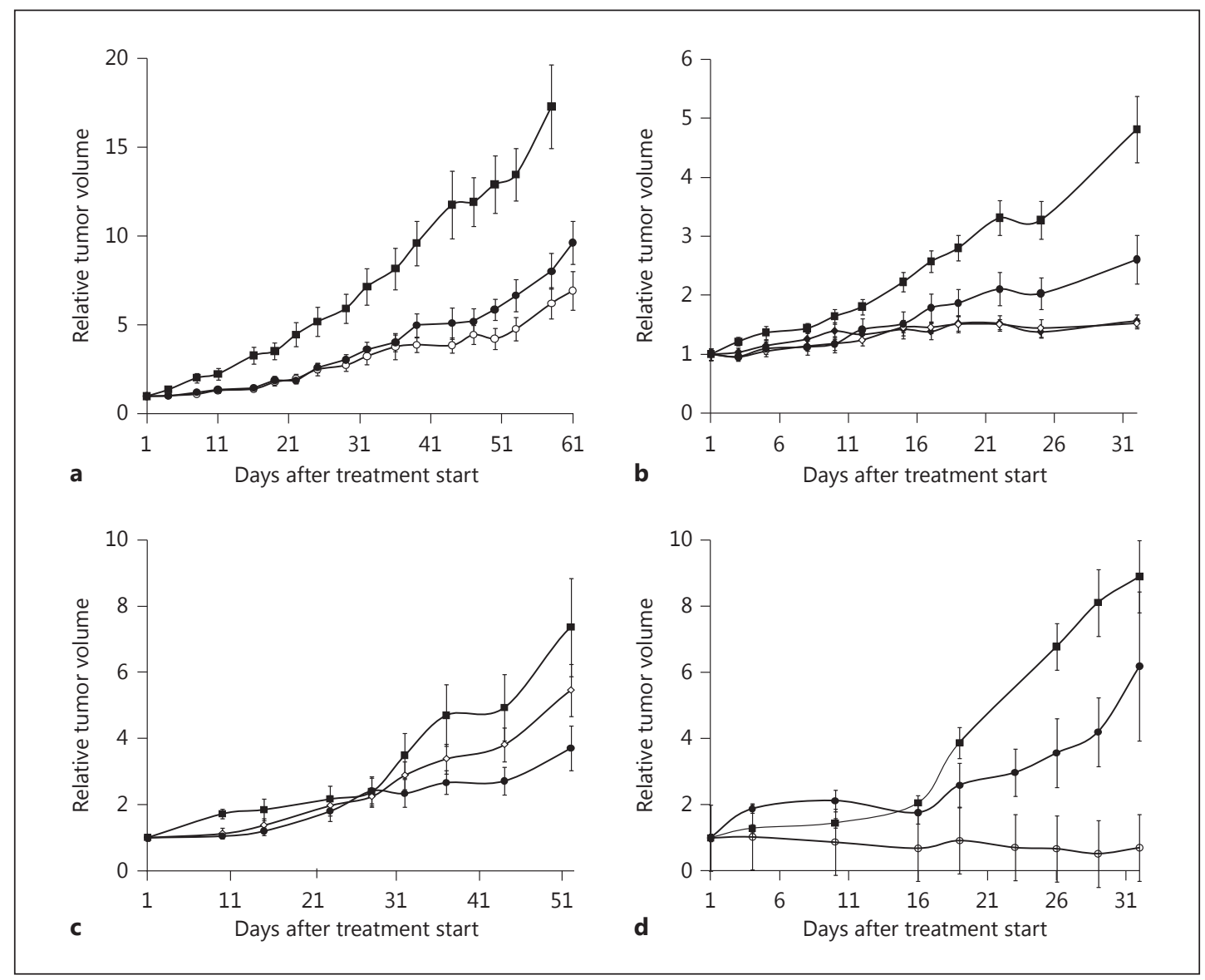

Fig. 3. In vivo responses of UM xenografts to bendamustine and other chemotherapeutic agents. Mice with PDX MP41 (a), MP46 (b), MP80 (c), and MM26 (d) were treated with bendamustine (11, 13, or $15 \mathrm{mg} / \mathrm{kg}$ per injection; closed circles), dacarbazine (open diamonds), temozolomide (closed diamonds), and fotemustine (open circles). Controls (closed squares) were treated with $0.9 \% \mathrm{NaCl}$. Tumor growth was evaluated by plotting the mean of the relative tumor volume \pm SD per group.

Fotemustine was used at an intraperitoneal dose of $30 \mathrm{mg} / \mathrm{kg}$ on days 1-3 every 3 weeks. We observed different responses among our UM PDXs, ranging from primary resistance to complete remission (fig. 2). We have also evaluated the efficacy of bendamustine, which is a cytotoxic agent containing the bifunctionally alkylating nitrogen mustard group and an additional purine nucleus. In 4 UM PDXs of our panel, bendamustine induced moderate tumor growth inhibition from 30 to 53\%, without any dose-response effect, and less efficiency than fotemustine (fig. 3). This preclinical trial was particularly interesting because our PDXs showed a high predictive value for the response to bendamustine of UM patients. Indeed, one clinical trial performed in metastatic UM patients did not find any efficacy in 9 evaluable cases [27].

\section{Conclusions}

Our data clearly indicate that our UM xenograft preclinical studies constitute relevant and predictive models for pharmacological assessments. According to the molecular assessment, our panel of xenografts can represent a valuable tool to test therapeutic efficacy 
Carita et al.: Uveal Melanoma Patient-Derived Xenografts

of standard and innovative treatments in humans. In the context of UM, in which a number of targeted therapies are currently under investigation [12], our models offer well-defined tumors in terms of mutational and genomic status, unregulated signalling pathways, as well as gene and protein expression. Based on these features, preclinical trials may hopefully define the best compound(s) and the best combination(s) of treatments to be translated into clinical trials. In this view, systematic genetic and molecular analysis of primary tumors is therefore recommended in the future, with material obtained from enucleations, transvitreal or transcleral needle biopsies to allow future adjuvant trials based on newly identified biological targets. Such approaches should thus improve the outcome of UM patients.

\section{References}

1 Decaudin D: Primary human tumor xenografted models ('tumorgrafts') for good management of patients with cancer. Anticancer Drugs 2011;22:827-841.

- Hollingshead MG: Antitumor efficacy testing in rodents. J Natl Cancer Inst 2008;100:1500-1510.

-3 Singh AD, Turell ME, Topham AK: Uveal melanoma: trends in incidence, treatment, and survival. Ophthalmology 2011;118:1881-1885.

4 Egan KM, Seddon JM, Glynn RJ, Gragoudas ES, and Albert DM: Epidemiologic aspects of uveal melanoma. Surv Ophthalmol 1988;32:239-251.

-5 Leyvraz S, Ulrich Keilholzb: Ocular melanoma: what's new? Curr Opin Oncol 2012;24:162-169.

6 Shah CP, Weis E, Lajous M, Shields JA, Shields CL: Intermittent and chronic ultraviolet light exposure and uveal melanoma: a meta-analysis. Ophthalmology 2005;112:1599-1607.

-7 Schmidt-Pokrzywniak A, Jöckel KH, Bornfeld N, Sauerwein W, Stang A: Positive interaction between light iris color and ultraviolet radiation in relation to the risk of uveal melanoma: a case-control study. Ophthalmology 2009;116:340-348.

-8 Kujala E, Mäkitie T, Kivelä T: Very long-term prognosis of patients with malignant uveal melanoma. Invest Ophthalmol Vis Sci 2003;44:4651-4659.

-9 Diener-West M, Reynolds SM, Agugliaro DJ, Caldwell R, Cumming K, Earle JD, Hawkins BS, Hayman JA, Jaiyesimi I, Jampol LM, Kirkwood JM, Koh WJ, Robertson DM, Shaw JM, Straatsma BR, Thoma J; Collaborative Ocular Melanoma Study Group: Development of metastatic disease after enrollment in the COMS trials for treatment of choroidal melanoma: collaborative Ocular Melanoma Study Group Report No. 26. Arch Ophthalmol 2005; 123:1639-1643.

10 Némati F, Sastre-Garau X, Laurent C, Couturier J, Mariani P, Desjardins L, Piperno-Neumann S, Lantz O, Asselain B, Plancher C, Robert D, Péguillet I, Donnadieu MH, Dahmani A, Bessard MA, Gentien D, Reyes C, Saule S, Barillot E, Roman-Roman S, Decaudin D: Establishment and characterization of a panel of human uveal melanoma xenografts derived from primary and/or metastatic tumors. Clin Cancer Res 2010;16:2352-2362.

11 Laurent C, Gentien D, Piperno-Neumann S, Némati F, Nicolas A, Tesson B, Desjardins L, Mariani P, Rapinat A, Sastre-Garau X, Couturier J, Hupé P, de Koning L, Dubois T, Roman-Roman S, Stern MH, Barillot E, Harbour JW, Saule S, Decaudin D: Patient-derived xenografts recapitulate molecular features of human uveal melanomas. Mol Oncol 2013;7:625-636.

12 Patel M, Smyth E, Chapman PB, Wolchok JD, Schwartz GK, Abramson DH, Carvajal RD: Therapeutic implications of the emerging molecular biology of uveal melanoma. Clin Cancer Res 2011;17:2087-2100.

13 Desjardins L, Levy-Gabriel C, Lumbroso-Lerouic L, Sastre X, Dendale R, Couturier J, Piperno-Neumann S, Dorval T, Mariani P, Salmon R, Plancher C, Asselain B: Prognostic factors for malignant uveal melanoma. Retrospective study on 2,241 patients and recent contribution of monosomy-3 research (in French). J Fr Ophtalmol 2006;29:741-749.

14 Damato B, Duke C, Coupland SE, Hiscott P, Smith PA, Campbell I, Douglas A, Howard P: Cytogenetics of uveal melanoma: a 7-year clinical experience. Ophthalmology 2007;114:1925-1931.

15 Kilic E, van Gils W, Lodder E, Beverloo HB, van Til ME, Mooy CM, Paridaens D, de Klein A, Luyten GP: Clinical and cytogenetic analyses in uveal melanoma. Invest Ophthalmol Vis Sci 2006;47:3703-3707.

16 Damato B, Dopierala JA, Coupland SE: Genotypic profiling of 452 choroidal melanomas with multiplex ligationdependent probe amplification. Clin Cancer Res 2010;16:6083-6092.

-17 Häusler T, Stang A, Anastassiou G, Jöckel KH, Mrzyk S, Horsthemke B, Lohmann DR, Zeschnigk M: Loss of heregozygosity of $1 p$ in uveal melanomas with monosomy 3. Int J Cancer 2005;116:909-913.

18 White JS, McLean IW, Becker RL, Director-Myska AE, Nath J: Correlation of comparative genomic hybridization results of 100 archival uveal melanomas with patient survival. Cancer Genet Cytogenet 2006;170:29-39.

19 Trolet J, Hupé P, Huon I, Lebigot I, Decraene C, Delattre O, Sastre-Garau X, Saule S, Thiéry JP, Plancher C, Asselain B, Desjardins L, Mariani P, Piperno-Neumann S, Barillot E, Couturier J: Genomic profiling and identification of high-risk uveal melanoma by array CGH analysis of primary tumors and liver metastases. Invest Ophthalmol Vis Sci 2009;50:2572-2580. 
Onken MD, Worley LA, Long MD, Duan S, Council ML, Bowcock AM, Harbour JW : Oncogenic mutations in GNAQ occur early in uveal melanoma. Invest Ophthalmol Vis Sci 2008;4:5230-5240.

-21 Bauer J, Kilic E, Vaarwater J, Bastian BC, Garbe C, de Klein A: Oncogenic GNAQ mutations are not correlated with disease-free survival in uveal melanoma. Br J Cancer 2009;101:813-815.

-22 Van Raamsdonk CD, Griewank KG, Crosby MB, Garrido MC, Vemula S, Wiesner T, Obenauf AC, Wackernagel W, Green G, Bouvier N, Sozen MM, Baimukanova G, Roy R, Heguy A, Dolgalev I, Khanin R, Busam K, Speicher MR, O’Brien J, Bastian BC: Mutations in GNA11 in uveal melanoma. N Engl J Med 2010;363:2191-2199.

-23 Harbour JW, Onken MD, Roberson ED, Duan S, Cao L, Worley LA, Council ML, Matatall KA, Helms C, Bowcock AM: Frequent mutation of BAP1 in metastazing uveal melanomas. Science 2010;330:1410-1413.

24 Harbour JW, Roberson ED, Anbunathan H, Onken MD, Worley LA, Bowcock AM: Recurrent mutations at codon 625 of the splicing factor SF3B1 in uveal melanoma. Nat Genet. 2013;45:133-135.

25 Pollock PM, Harper UL, Hansen KS, Yudt LM, Stark M, Robbins CM, Moses TY, Hostetter G, Wagner U, Kakareka J, Salem G, Pohida T, Heenan P, Duray P, Kallioniemi O, Hayward NK, Trent JM, Meltzer PS: High frequency of BRAF mutations in nevi. Nat Genet 2003;33:19-20.

26 Onken MD, Worley LA, Char DH, Augsburger JJ, Correa ZM, Nudleman E, Aaberg TM Jr, Altaweel MM, Bardenstein DS, Finger PT, Gallie BL, Harocopos GJ, Hovland PG, McGowan HD, Milman T, Mruthyunjaya P, Simpson ER, Smith ME, Wilson DJ, Wirostko WJ, Harbour JW : Collaborative ocular oncology group report number 1:prospective validation of a multi-gene prognostic assay in uveal melanoma. Ophthalmology 2012;119: 1596-1603.

27 Schmidt-Hieber M, Schmittel A, Thiel E, Keilholz U: A phase II study of bendamustine chemotherapy as secondline treatment in metastatic uveal melanoma. Melanoma Res 2004;14:439-442. 